\title{
Reach and Validity of an Objective Medication Adherence Measure Among Safety Net Health Plan Members with Diabetes: A Cross-Sectional Study
}

\author{
Neda Ratanawongsa, MD, MPH; Andrew J. Karter, PhD; Judy Quan, PhD; \\ Melissa M. Parker, MS; Margaret Handley, PhD, MPH; Urmimala Sarkar, MD, MPH; \\ Julie A. Schmittdiel, PhD; and Dean Schillinger, MD
}

\begin{abstract}
BACKGROUND: With the expansion of Medicaid and low-cost health insurance plans among diverse patient populations, objective measures of medication adherence using pharmacy claims could advance clinical care and translational research for safety net care. However, safety net patients may experience fluctuating prescription drug coverage, affecting the performance of adherence measures.
\end{abstract}

OBJECTIVE: To evaluate the performance of continuous medication gap (CMG) for diverse, low-income managed care members with diabetes.

METHODS: We conducted this cross-sectional analysis using administrative and clinical data for 680 members eligible for a self-management support trial at a nonprofit, government-sponsored managed care plan. We applied CMG methodology to cardiometabolic medication claims for English- , Cantonese- , or Spanish-speaking members with diabetes. We examined inclusiveness (the proportion with calculable CMG) and selectivity (sociodemographic and medical differences from members without CMG). For validity, we examined unadjusted associations of suboptimal adherence (CMG $>20 \%$ ) with suboptimal cardiometabolic control.

RESULTS: 429 members (63\%) had calculable CMG. Compared with members without CMG, members with CMG were younger, more likely employed, and had poorer glycemic control but had better blood pressure and lipid control. Suboptimal adherence occurred more frequently among members with poor cardiometabolic control than among members with optimal control ( $28 \%$ vs. $12 \%, P=0.02)$.

CONCLUSIONS: CMG demonstrated acceptable inclusiveness and validity in a diverse, low-income safety net population, comparable with its performance in studies among other insured populations. CMG may provide a useful tool to measure adherence among increasingly diverse Medicaid populations, complemented by other strategies to reach those not captured by CMG.

J Manag Care Spec Pharm. 2015;21(8):688-98

Copyright $\odot 2015$, Academy of Managed Care Pharmacy. All rights reserved.

\section{What is already known about this subject}

Medication-related conversations often get derailed based on faulty provider assumptions about patient adherence, resulting in missed opportunities to strategize about nonadherence or inappropriate decisions about intensification.
Continuous medication gap (CMG) is an objective measure of adherence that uses pharmacy dispensings to measure gaps in patients' available supply of medications, but the validity of CMG relies on the assumption of complete capture of pharmacy utilization.

The expansion of Medicaid and low-cost health insurance plans prompted by the 2010 Patient Protection and Affordable Care Act will increase access to prescription drug coverage for patients with chronic illnesses, especially those from racial/ethnic minorities.

\section{What this study adds}

CMG demonstrated acceptable inclusiveness and validity in a diverse, low-income safety net population, comparable to its performance in other insured populations.

Applying CMG to Medicaid and low-income health plan pharmacy claims may provide a useful tool for safety net health care systems to measure adherence among linguistically and culturally diverse populations.

When attempting to measure adherence for quality improvement or intervention work, as well as research in a safety net population, health plans and health systems will need to examine other means of evaluating adherence for those for whom CMG is not calculable.

O ublic health safety net systems serve high proportions of low-income and racial/ethnic minorities with high diabetes prevalence and poor clinical outcomes. ${ }^{1-3}$ Treatment with hypoglycemic, antihypertensive, and lipid-lowering medications has been shown to reduce morbidity and mortality in people with diabetes. ${ }^{4}$ Suboptimal adherence to medications, however, contributes significantly to suboptimal cardiometabolic control and poor clinical outcomes. ${ }^{5-8}$ When caring for patients with suboptimal cardiometabolic control, clinicians are expected to assess adherence to current therapies, engage in patient-centered conversations about patient goals, elicit treatment preferences and burdens, and discuss options to modify or intensify regimens. ${ }^{9-11}$ Improved medication adherence has been linked to patient-provider communication and shared decision making. ${ }^{12,13}$ However, these medication-related conversations often get derailed because of faulty provider 
assumptions about patient adherence, resulting in missed opportunities to strategize about nonadherence or inappropriate decisions about intensification. ${ }^{6,7,14-21}$

Safety net health care systems and providers may benefit from tools that assess patient adherence to cardiometabolic medications. Continuous medication gap (CMG) is an objective measure of adherence that uses pharmacy dispensings to measure gaps in patients' available supply of medications. ${ }^{22,23}$ In U.S. integrated health care delivery systems such as Kaiser Permanente and the Veterans Affairs system, CMG has been well validated against electronic pill cap monitoring, serum/ urine drug levels, physiological drug effects, change in clinical control, and comorbidity and cost. ${ }^{8,22,24}$ The validity of CMG relies on the assumption of complete capture of pharmacy utilization because any underascertained utilization will be falsely interpreted as nonadherence (i.e., a directional bias). CMG performs well when plans incentivize patients to obtain all prescriptions at health plan pharmacies, ${ }^{8}$ and in claimbased insurance systems without closed pharmacy systems, CMG may be captured accurately while health plan members maintain continuous prescription benefits. ${ }^{22,23,25}$ Because of its potential to guide clinical decision making, CMG has been provided to pharmacists in managed care settings as a real-time indicator of adherence to target adherence and intensification interventions to improve blood pressure control., 26

The expansion of Medicaid and low-cost health insurance plans prompted by the 2010 Patient Protection and Affordable Care Act will increase access to prescription drug coverage for patients with chronic illnesses, especially those from racial/ ethnic minorities. ${ }^{27-31}$ This increased access will yield new opportunities to measure adherence among safety net populations, with increasing accessibility of pharmacy claims for broader and more diverse populations. However, safety net patients may experience fluctuating membership and thus prescription drug coverage, which may occur differentially across sociodemographic groups..$^{32-34}$

If found to have broad reach and acceptable validity, comparable to other insured populations, CMG could serve as an important tool for clinical care and translational research for safety net populations. However, prior research has not examined the important questions of "who is in" and "who is out" of CMG measurement and the validity of CMG in a diverse, lowincome safety net population. Thus, we aimed to determine the inclusiveness, selectivity, and validity of CMG methodology to detect objectively inadequate medication adherence in an ethnically diverse safety net population of Medicaid and lowincome managed care plan members with diabetes.

\section{Methods}

For this cross-sectional analysis, we applied the CMG methodology to data collected as part of the SMARTSteps Program, a quasi-experimental study of a self-management health infor- mation technology intervention for San Francisco Health Plan (SFHP) members with diabetes. ${ }^{35,36}$ This study used a waitlist variant of a stepped wedge design, in which SFHP randomized participants to immediate or waitlist intervention during 4 recruitment waves (April 2009-March 2011); waitlist participants crossed over to intervention after 6 months.

\section{Study Setting}

SFHP (http://www.sfhp.org/) is a nonprofit, government-sponsored managed care plan created to underwrite medical care to low-income San Francisco residents. In addition to managing Medicaid benefits, SFHP administers "Healthy Workers," an insurance program for low-income people working as in-home support service providers for elderly or disabled people in San Francisco. Thus, SFHP administers benefits for a large proportion of patients served by the Community Health Network of San Francisco (CHNSF), which is the public health department's integrated health care delivery system. CHNSF is part of the San Francisco Bay Area Collaborative Research Network (http://www.sfbaycrn.org).

SMARTSteps eligibility criteria included English-, Cantonese-, or Spanish-speaking adults (aged $\geq 18$ years) with diabetes and $\geq 1$ primary care visits in the preceding 24 months to 1 of 4 CHNSF clinics based on CHNSF registry data. Members who were pregnant, lacked a touch-tone phone, reported plans to leave the region, or were unable to provide verbal consent were ineligible. We identified diabetes patients through the CHNSF diabetes registry or those with evidence of SFHP claims related to diabetes, followed by confirmation in the CHNSF electronic health record (clinician-documented diagnosis of diabetes, fasting glucose $\geq 126$ milligrams per deciliter $[\mathrm{mg} / \mathrm{dL}]$, or hemoglobin $\mathrm{Alc}[\mathrm{Alc}] \geq 7 \%) .{ }^{37}$ We excluded SFHP members who denied having diabetes during recruitment calls

\section{Data Sources}

Data sources for this analysis included SFHP administrative data (January 1, 2008-February 29, 2012), CHNSF clinical registry data (January 1, 2008-February 29, 2012), and participant interviews conducted at baseline for the SMARTSteps evaluation (April 2009-March 2011).

For all SFHP members who were potentially eligible for SMARTSteps, we had SFHP administrative data (age, gender, race/ethnicity, language, financial class/insurance type, and pharmacy claims) and CHNSF clinical registry data (Alc, systolic blood pressure [SBP], diastolic blood pressure [DBP], and low-density lipoprotein [LDL]) obtained through routine care.

Members who enrolled in SMARTSteps also participated in structured, computer-assisted telephone interviews administered by bilingual research assistants from University of California, San Francisco, who obtained verbal consent by telephone. During the baseline interview $(n=278)$, participants 
reported their educational attainment, employment status, and annual household income and screened for English proficiency and health literacy using items validated for this population. ${ }^{38-40}$ Participants received a $\$ 50$ gift card for each interview. The Committee on Human Research at the University of California, San Francisco, approved the evaluation component of the SMARTSteps program. This study is registered as NCT00683020 at Clinicaltrials.gov.

\section{Continuous Medication Gap}

CMG is a well-established measure of secondary adherence for ongoing medications using pharmacy data. ${ }^{22,23}$ The validity of the CMG depends, in part, on complete data capture-that is, patients obtain all prescriptions within the insurance system from which claims are drawn and have continuous prescription benefits throughout a defined observation period. ${ }^{22,23,25}$ CMG is calculated only if the medication is filled by patients at least 2 times during the capture period. This implies that the patient completed at least 1 bounded "refill interval," which refers to the elapsed time between 2 fills. The frequency of fills depends inversely on the days' supply prescribed-that is, a 30-day prescribed supply is expected to accrue fills more quickly than a 90-day prescribed supply. (Of note, SFHP does not mandate a switch to mail order for chronic medication refills.) CMG estimates the proportion of days without sufficient medication supply within each refill interval and then sums those for all refill intervals occurring between the first pharmacy dispensing during the measurement period and the last dispensing within the measurement period.

To confirm that the prescription is used as an ongoing treatment, rather than a newly initiated treatment, we included only medications with at least 2 fills during the prior 12 months, followed by at least 2 fills during the 12-month observation period in which CMG was measured. We used a modified approach that accounts for stockpiling medications using a time-forward algorithm (i.e., extra pills remaining after any given refill do not negate gaps in medication supply occurring during previous refill intervals, but they are included in the count of future medication supply). ${ }^{25}$ Because pharmacy utilization data does not provide insulin fixed days supply based on prescribed dosing, we excluded insulin prescription refills, similar to other studies. ${ }^{7,13}$

In this analysis, CMG was deemed calculable for SMARTSteps-eligible SFHP members with the following: (a) active pharmacy benefits between January 1, 2008, and February 29, 2012 (from which claims were drawn to establish baseline periods for ongoing medications as well as the CMG capture periods); (b) claims for at least 1 oral diabetes, hypertension, or hyperlipidemia medication with the number of fills required as previously mentioned; and (c) $\geq 1$ claims for an oral hypoglycemic medication or insulin, as an additional confirmation of diabetes diagnosis. CMG was not calculable for dually eligible Medicaid/Medicare beneficiaries, whose alternative pharmacy benefit coverage prohibits complete ascertainment of pharmacy claims.

Given concerns that safety net patients may have periodic disruptions in their membership benefits, we conducted a sensitivity analysis to determine how results would have differed with a 24-month continuous benefit requirement. ${ }^{28,41-44}$

For each subject, we calculated the CMG for all indications combined and separately by indication (i.e., CMG for oral diabetes medications only, hypertension medications only, and hyperlipidemia medications only). Using a previously validated classification, we considered patients as having suboptimal adherence when subjects lacked a medication supply $>20 \%$ of the observation time, and adherent when medications were available for $80 \%$ or more of the time..$^{8,45,46}$

First, we evaluated the inclusiveness of CMG by calculating the proportion of population with a calculable CMG. We then evaluated the selectivity of CMG by characterizing whether sociodemographic factors and cardiometabolic control were associated with having or not having a calculable CMG for 12 months, using chi-square tests or Fisher's exact tests for categorical variables, t-tests for normally distributed interval variables, and Wilcoxon tests for interval variables without a normal distribution.

Second, for subjects for which we were able to calculate CMG, we estimated the proportion with suboptimal adherence. We then compared sociodemographic characteristics for those with suboptimal versus optimal adherence.

Third, we evaluated CMG's construct validity (ability to predict a construct that a measure should theoretically be able to predict) by examining its relationship to cardiometabolic control in the sample with calculable CMG in bivariate analyses. We used the first cardiometabolic measures obtained during the CMG capture periods, defining suboptimal control with low cutpoints (Alc $\geq 7.0 \%, \mathrm{SBP} \geq 130$ millimeters of mercury $[\mathrm{mmHg}], \mathrm{DBP} \geq 80 \mathrm{mmHg}$, and $\mathrm{LDL} \geq 100 \mathrm{mg} / \mathrm{dL}$ ) and high cutpoints (Alc $\geq 9.0 \%, \mathrm{SBP} \geq 140 \mathrm{mmHg}, \mathrm{DBP} \geq 90 \mathrm{mmHg}$, and $\mathrm{LDL} \geq 130 \mathrm{mg} / \mathrm{dL}$ ). We then compared the prevalence of suboptimal adherence (CMG> 20\%) for members with suboptimal versus optimal cardiometabolic control overall (on at least 1 of the previous measures) and for each therapeutic indication. We repeated these analyses stratifying by age (aged $<55$ years vs. aged $\geq 55$ years), gender, language, race/ethnicity, and financial class/insurance type to verify whether the relationship between CMG and cardiometabolic control was similar across these prespecified subgroups. Although we lacked power for these subgroup analyses, we sought to confirm that the relationships occurred in the hypothesized direction among diverse subsets of the population. 


\section{Results}

\section{Inclusiveness and Selectivity}

Figure 1 depicts the flow diagram for this analysis. Among potentially eligible SMARTSteps participants $(n=910), 230$ were determined to be ineligible based on lack of active SFHP membership, lack of diabetes, primary clinic, language, plans to move, or no longer alive. ${ }^{35}$ Among the remaining 680 patients, 429 (63.1\%) had a calculable CMG. Reasons for noncalculable CMG were as follows: 35 (5.1\%) had Medicare and therefore may have received medications through a Medicare pharmacy plan; 90 (13.2\%) lacked any claim for hypoglycemic medications; 35 (5.1\%) lacked any pharmacy claim during the first 12 months; 18 (2.6\%) had only 1 pharmacy claim during the first 12 months; and 73 (10.7\%) had fewer than 2 pharmacy claims during the second 12 months.

Compared with those without calculable CMG (Table 1), members with $C M G$ were younger $(P=0.02)$ and were more likely to have Healthy Worker/Healthy San Francisco coverage than Medicaid, commercial insurance, or no coverage $(P<0.001)$. A greater proportion of members with $C M G$ also had poorer glycemic control but better blood pressure and lipid control, compared with members without calculable CMG. Among the subset with baseline interview data $(n=278)$, compared with those without CMG, a higher proportion of members with $C M G$ were employed full or part time $(P=0.006)$. We found no significant differences by race/ethnicity, language, gender, income, education, English proficiency, or health literacy. Seventy-three members had fewer than 2 pharmacy claims in the CMG capture period; compared with the calculable CMG group, a higher proportion of those with noncalculable CMG were non-English speaking $(P=0.009)$ and had Medicaid $(P=0.01)$.

Among the 429 members with a calculable CMG, 113 (26.3\%) had suboptimal adherence (CMG $>20 \%)$. Higher proportions of members with suboptimal adherence were Black or Hispanic versus other race/ethnicities; English- or Spanishspeaking versus Cantonese-speaking; and had Medicaid insurance versus other coverage (Table 2).

\section{Validity}

Among those with a calculable CMG, 395 (92.1\%) also had available cardiometabolic data during the CMG capture period. In this cohort, 102 (25.8\%) had suboptimal adherence for all cardiometabolic medications combined (Figure 2). Suboptimal adherence was more frequent among those with suboptimal cardiometabolic control than among those with optimal control, using high cutpoints (56 [34.6\%] vs. 33 [16.6\%], $P<0.001$ ) and low clinical cutpoints (96 [27.8\%] vs. 6 [12.2\%], $P=0.02$ ). By therapeutic indication, 89 (26.0\%) members had suboptimal adherence for oral diabetes medications-62 (21.5\%) for anti- hypertensives and 556 (23.0\%) for lipid-lowering medications. The association between suboptimal adherence and suboptimal control was significant across all therapeutic indications for high cutpoints. The prevalence of suboptimal adherence to oral diabetes medications was 39.1\% for those with Alc $\geq 9.0 \%$, compared with $24.0 \%$ suboptimal adherence among those with lower Alc $(P=0.03)$. The prevalence of suboptimal adherence to hypertension medications was $32.9 \%$ for those with $\mathrm{SBP} \geq 140 \mathrm{mmHg}$ and/or $\mathrm{DBP} \geq 90 \mathrm{mmHg}$, compared with $16.7 \%$ suboptimal adherence among those with lower blood pressures $(P=0.002)$. The prevalence of suboptimal adherence to hyperlipidemia medications was $50.0 \%$ for those with $\mathrm{LDL} \geq 130 \mathrm{mg} / \mathrm{dL}$, compared with $20.8 \%$ suboptimal adherence among those with $\mathrm{LDL}<130 \mathrm{mg} / \mathrm{dL}(P=0.008)$. At low cutpoints, the relationship between suboptimal adherence and suboptimal control was in the hypothesized direction for each therapeutic indication but was only statistically significant for hyperlipidemia.

The direction of the relationship between suboptimal adherence and suboptimal cardiometabolic control was consistent across age, gender, language, race/ethnicity, and insurance type for all cardiometabolic measures combined, but because of small sample sizes, the associations were only statistically significant in some analyses (Table 3).

In a sensitivity analysis, we found that higher proportions of members with CMG calculated with 24 months of continuous benefits had limited English proficiency $(P=0.02)$ and limited health literacy $(P=0.02)$; were employed $(P<0.001)$; and reported incomes $>\$ 20,000(P=0.02)$, compared with those without CMG (data not shown).

\section{Discussion}

We conducted this study to determine the inclusiveness, selectivity, and validity of CMG as an objective measure of adherence for application in safety net populations and to determine whether it could perform in ways comparable with other insured populations. To our knowledge, this is the first attempt to assess these characteristics of CMG applied to claims data from a health plan that provides coverage to Medicaid and low-income, diverse beneficiaries. Our findings suggest that the CMG methodology provides a modestly inclusive and a valid measure for medication adherence among a diverse urban population covered by a government-sponsored managed care plan.

A potential concern for using prescription claims data in safety net populations is the inability to calculate CMG among the most vulnerable subsets of this population, whose coverage lapses or who lack sufficient refill intervals due to communication barriers. For example, patients with limited health literacy or limited English proficiency could be at higher risk for insurance coverage instability due to difficulties completing the reenrollment forms and procedures. ${ }^{28,41-44}$ In addition, patients 
Reach and Validity of an Objective Medication Adherence Measure Among

Safety Net Health Plan Members with Diabetes: A Cross-Sectional Study

\section{FIGURE 1 Medication Adherence Analysis Cohort of Low-Income Health Plan Members with Diabetes}

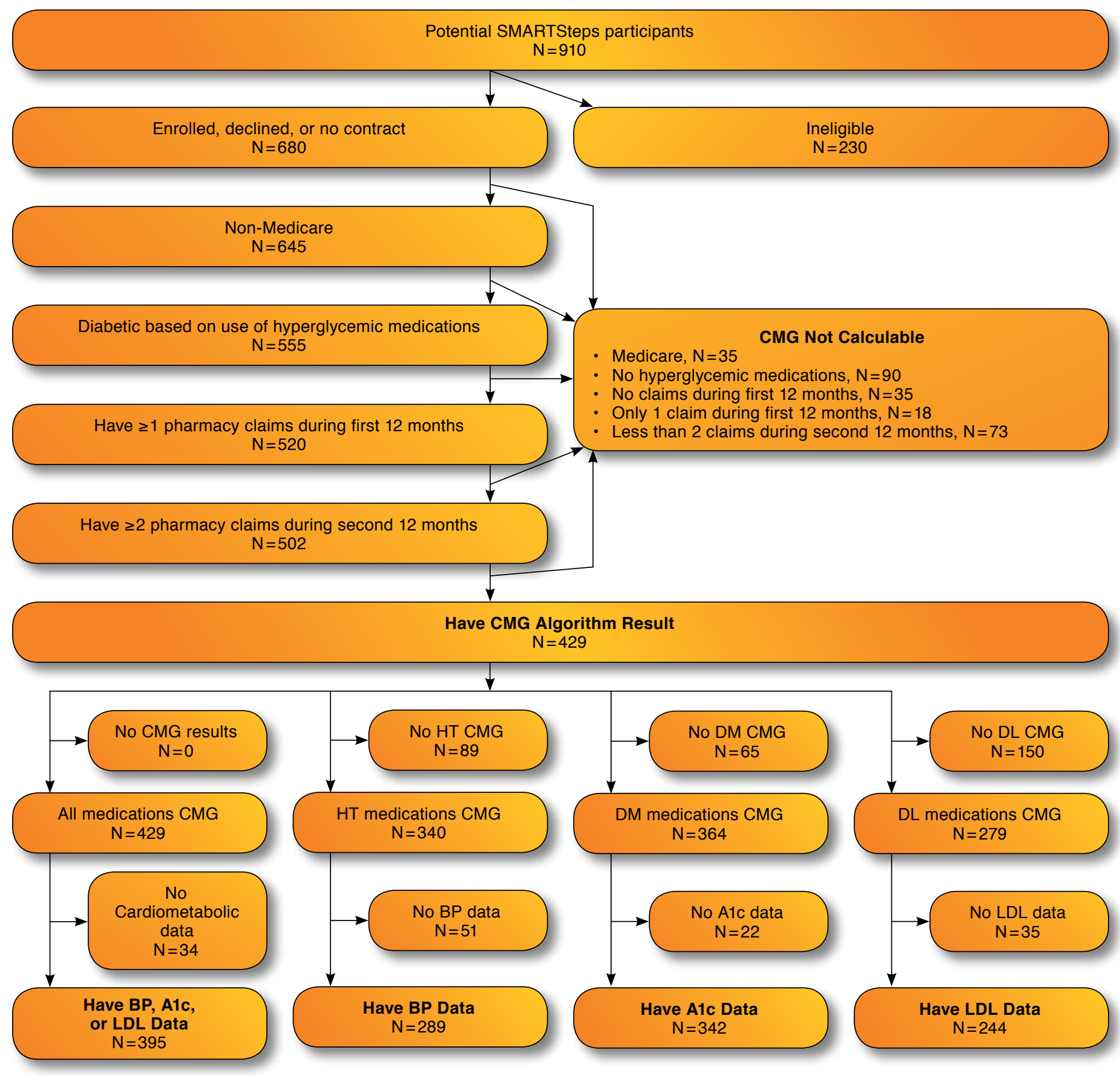

Alc=hemoglobin $A 1 c ; B P=$ blood pressure $C M G=$ continuous medication gap; $D L=$ dyslipdemia DM = diabetes; $H T=$ hypertension; $L D L=$ low-density lipoprotein; SMARTSteps = quasi-experimental study of a self-management health information technology intervention for San Francisco Health Plan members with diabetes.

with limited English proficiency and limited health literacy may experience confusion with medication counseling, which can lead to failure to obtain a second prescription refill. ${ }^{47-51}$
We were able to calculate a CMG on $63 \%$ of members, a figure comparable with the $69 \%$ with calculable CMG in an ethnically diverse Northern California managed care 
TABLE 1 Sociodemographic and Medical Characteristics for Low-Income Diabetic Health Plan Members With and Without a Calculable Continuous Medication Gap

\begin{tabular}{|c|c|c|c|c|c|c|c|}
\hline \multirow{2}{*}{$\begin{array}{l}\text { Characteristics }^{\mathbf{a}} \\
\text { Age in years, mean (SD) }\end{array}$} & \multicolumn{2}{|c|}{$\begin{array}{l}\text { Cohort } \\
(\mathrm{N}=680)\end{array}$} & \multicolumn{2}{|c|}{$\begin{array}{l}\text { With CMG } \\
(\mathrm{N}=429)\end{array}$} & \multicolumn{2}{|c|}{$\begin{array}{l}\text { Without CMG } \\
\quad(\mathrm{N}=251)\end{array}$} & \multirow{2}{*}{$\frac{P \text { Value }^{\text {b }}}{0.020}$} \\
\hline & 55.4 & $(9.3)$ & 55.1 & $(7.9)$ & 56.1 & $(11.1)$ & \\
\hline Female & 460 & $(67.6)$ & 291 & $(67.8)$ & 169 & $(67.3)$ & 0.890 \\
\hline Race/ethnicity & & & & & & & 0.080 \\
\hline Asian/Pacific Islander & 391 & $(57.5)$ & 253 & $(59.0)$ & 138 & $(55.0)$ & \\
\hline Hispanic & 132 & (19.4) & 83 & (19.3) & 49 & $(19.5)$ & \\
\hline White & 82 & $(12.1)$ & 55 & $(12.8)$ & 27 & $(10.8)$ & \\
\hline Black & 53 & $(7.8)$ & 24 & $(5.6)$ & 29 & $(11.6)$ & \\
\hline Native American/multiethnic/other & 22 & (3.2) & 14 & (3.3) & 8 & $(3.2)$ & \\
\hline Language & & & & & & & 0.950 \\
\hline Cantonese & 305 & $(44.9)$ & 194 & $(45.2)$ & 111 & $(44.2)$ & \\
\hline English & 279 & $(41.0)$ & 174 & $(40.6)$ & 105 & $(41.8)$ & \\
\hline Spanish & 96 & $(14.1)$ & 61 & $(14.2)$ & 35 & (13.9) & \\
\hline Financial class/insurance type & & & & & & & $<0.001$ \\
\hline Healthy Worker/SF & 469 & $(69.0)$ & 319 & $(74.4)$ & 150 & $(59.8)$ & \\
\hline Medicaid & 167 & $(24.6)$ & 106 & $(24.7)$ & 61 & $(24.3)$ & \\
\hline Commercial/uninsured & 9 & (1.3) & 4 & $(0.9)$ & 5 & $(2.0)$ & \\
\hline Medicare & 35 & $(5.1)$ & 0 & $(0.0)$ & 35 & (13.9) & \\
\hline Education $\leq 8$ th grade $^{\mathrm{c}}$ & 118 & $(42.4)$ & 90 & $(45.0)$ & 28 & $(35.9)$ & 0.530 \\
\hline Employed full or part time $e^{c}$ & 190 & $(68.3)$ & 147 & $(73.5)$ & 43 & $(55.1)$ & 0.006 \\
\hline Annual household income $\leq \$ 20,000^{c}$ & 170 & $(64.6)$ & 118 & $(62.4)$ & 52 & $(70.3)$ & 0.190 \\
\hline Limited English proficiencyc & 189 & $(68.0)$ & 138 & $(69.0)$ & 51 & $(65.4)$ & 0.100 \\
\hline Limited health literacyc & 118 & $(42.6)$ & 86 & $(43.2)$ & 32 & $(41.0)$ & 0.740 \\
\hline Hemoglobin Alc, mean (SD) & 7.63 & $(1.6)$ & 7.65 & $(1.5)$ & 7.57 & $(1.9)$ & 0.005 \\
\hline Hemoglobin Alc $\geq 7.0 \%$ & 348 & $(60.3)$ & 259 & $(64.9)$ & 89 & $(50.0)$ & $<0.001$ \\
\hline Hemoglobin Alc $\geq 9.0 \%$ & 85 & $(14.7)$ & 57 & $(14.3)$ & 28 & $(15.7)$ & 0.650 \\
\hline Systolic blood pressure, mean (SD) & 130.4 & $(18.4)$ & 129.5 & $(18.3)$ & 132.6 & $(18.5)$ & 0.080 \\
\hline Systolic blood pressure $\geq 130 \mathrm{mmHg}$ & 253 & $(48.7)$ & 178 & $(48.4)$ & 75 & $(49.7)$ & 0.790 \\
\hline Systolic blood pressure $\geq 140 \mathrm{mmHg}$ & 151 & $(29.1)$ & 96 & $(26.1)$ & 55 & $(36.4)$ & 0.020 \\
\hline Diastolic blood pressure, mean (SD) & 75.5 & $(10.8)$ & 75.0 & $(10.6)$ & 76.8 & $(11.2)$ & 0.060 \\
\hline Diastolic blood pressure $\geq 80 \mathrm{mmHg}$ & 171 & $(32.9)$ & 112 & $(30.4)$ & 59 & $(39.1)$ & 0.060 \\
\hline Diastolic blood pressure $\geq 90 \mathrm{mmHg}$ & 44 & $(8.5)$ & 27 & $(7.3)$ & 17 & $(11.3)$ & 0.150 \\
\hline Low-density lipoprotein, mean (SD) & 93.6 & $(32.4)$ & 91.5 & $(31.2)$ & 98.3 & $(34.5)$ & 0.030 \\
\hline Low-density lipoprotein $\geq 100 \mathrm{mg} / \mathrm{dL}$ & 191 & $(36.5)$ & 117 & $(32.6)$ & 74 & $(44.8)$ & 0.007 \\
\hline Low-density lipoprotein $\geq 130 \mathrm{mg} / \mathrm{dL}$ & 78 & (14.9) & 45 & $(12.5)$ & 33 & $(20.0)$ & 0.030 \\
\hline
\end{tabular}

aAll information in this table is presented as number and percentage unless otherwise indicated.

${ }^{b} P$ values derived from chi-square tests or Fisher's exact tests for categorical variables, t-tests for normally distributed interval variables, and Wilcoxon tests for interval variables without a normal distribution (age and cardiometabolic data).

'For patients who completed SMARTSteps baseline interview $(n=278)$

$C M G=$ continuous medication gap; Healthy Worker/SF=Healthy Worker/San Francisco; $m g / d L=$ millimeter per deciliter; $m m H g=$ millimeter of mercury; $S D=$ standard deviation; SMARTSteps = quasi-experimental study of a self-management health information technology intervention for San Francisco Health Plan members with diabetes.

population with predominantly commercial or Medicare plans. ${ }^{8}$ In our analysis, we found no significant differences between those with and without a calculable CMG by language, gender, income, education, English proficiency, or health literacy. Thus, patients with traditional communication barriers such as limited English-proficiency and limited health literacy may be assessed by traditional objective adherence measures. We were concerned that patients with communication barriers would be at higher risk for failure to refill medications and thus having fewer than 2 claims in the CMG capture period; among these
73 patients, 83\% were non-English-speaking patients, suggesting that those patients could be at higher risk for falling out of the CMG measure on that criterion. The selectivity of CMG does appear to have been reduced by eliminating a need for 24 months of continuous pharmacy benefits. The race/ethnicity difference between those with and without a calculable CMG was also not statistically significant; however, given that over half of African-Americans in our sample did not have calculable CMG, racial/ethnic disparities in CMG availability should be explored in future studies. 


\begin{tabular}{|c|c|c|c|}
\hline \multirow{2}{*}{ Characteristics $^{\mathrm{a}}$} & \multirow[b]{2}{*}{$\begin{array}{l}\text { Suboptimal } \\
\text { Adherence } \\
(\mathrm{N}=113)\end{array}$} & \multirow[b]{2}{*}{$\begin{array}{c}\text { Optimal } \\
\text { Adherence } \\
(\mathrm{N}=316)\end{array}$} & \multirow[b]{2}{*}{$\begin{array}{c}P \\
\text { Value }^{b}\end{array}$} \\
\hline & & & \\
\hline Age in years, mean (SD) & $53.7 \quad(9.7)$ & $55.6 \quad(7.2)$ & 0.100 \\
\hline Female & $74(65.5)$ & $217(68.7)$ & 0.530 \\
\hline Race/ethnicity & & & 0.002 \\
\hline Asian/Pacific Islander & $51(45.1)$ & $202(63.9)$ & \\
\hline Hispanic & $31(27.4)$ & $52(16.5)$ & \\
\hline White & $14(12.4)$ & $41(13.0)$ & \\
\hline Black & $11 \quad(9.7)$ & $13 \quad(4.1)$ & \\
\hline Native American/multiethnic/other & $6 \quad(5.3)$ & $8 \quad(2.5)$ & \\
\hline Language & & & $<0.001$ \\
\hline Cantonese & $34(30.1)$ & $160(50.6)$ & \\
\hline English & $57(50.4)$ & $117(37.0)$ & \\
\hline Spanish & $22(19.5)$ & $39(12.3)$ & \\
\hline Financial class/insurance type & & & 0.001 \\
\hline Healthy Worker/SF & $70(61.9)$ & $249(78.8)$ & \\
\hline Medi-Cal & $41(36.3)$ & $65(20.6)$ & \\
\hline Commercial/uninsured & $2(1.8)$ & $2(0.6)$ & \\
\hline Education $\leq 8$ th grade ${ }^{c}$ & $14(37.8)$ & $76(46.6)$ & 0.380 \\
\hline Employed full or part timec & $27(72.9)$ & $120(73.6)$ & 0.930 \\
\hline Annual household income $\leq \$ 20,000^{c}$ & $22(61.1)$ & $96(62.7)$ & 0.980 \\
\hline Limited English proficiencyc & $26(70.3)$ & $112(68.7)$ & 0.260 \\
\hline Limited health literacyc & $14(37.8)$ & $72(44.4)$ & 0.460 \\
\hline \multicolumn{4}{|c|}{$\begin{array}{l}\text { bP values derived from chi-square tests or Fisher's exact tests for categorical vari- } \\
\text { ables, } t \text {-tests for normally distributed interval variables, and Wilcoxon tests for } \\
\text { interval variables without a normal distribution (age). } \\
\text { 'For patients who completed SMARTSteps baseline interview }(n=239) \text {. } \\
\text { Healthy Worker/SF=Healthy Worker/San Francisco; SMARTSteps = quasi-exper- } \\
\text { imental study of a self-management health information technology intervention for } \\
\text { San Francisco Health Plan (SFHP) members with diabetes. }\end{array}$} \\
\hline
\end{tabular}

Our findings suggest that when attempting to measure adherence for quality improvement or intervention work, as well as research in a safety net population, health plans and health systems will need to examine other means of evaluating adherence for those for whom CMG is not calculable. The reach of CMG did differ by other patient sociodemographic factors, with calculable CMG available more commonly for those who were younger, employed, or had Healthy Workers or Healthy San Francisco. CMG was less available for those who had suboptimal blood pressure and lipid control. Other measures of medication adherence should be studied for validity and reliability in diverse populations, including self-reported adherence, other patient assessment strategies such as automated telephony, or clinician interpretation of time between recent refills. $8,13,52$

Rates of nonadherence were comparable with those found in studies of insured, diverse higher-income Northern California populations and diverse populations in other managed care settings, whose published nonadherence rates range from 20\%$30 \% .7,8,13,53$ While suboptimal adherence occurred at higher rates in certain sociodemographic subgroups, our findings suggest that this safety net population may experience similar overall rates of nonadherence to other insured populations.

The validity of CMG in this population is suggested by our findings that suboptimal adherence was associated with cardiometabolic control overall and for suboptimal cardiometabolic control for each therapeutic indication. CMG has been validated in comparison with more resource-intensive monitoring systems and with clinical measures in integrated health care delivery systems such as Kaiser Permanente and the Veterans Affairs system. ${ }^{8,22,24}$ Our findings were similar to a Michigan study, which found the strongest relationships between cardiometabolic outcomes and hyperlipidemia medication nonadherence..$^{54}$ Suboptimal adherence was also associated with cardiometabolic control similarly across sociodemographic subgroups, supporting its potential for use in safety net systems as a real-time indicator of adherence. ${ }^{9,26}$ Clinicians are often inaccurate in assessing adherence among their patients and view medication benefits and burdens differently from their patients. ${ }^{14,15,55,56}$ This may result in potential missed opportunities to strategize about nonadherence; incorrectly intensifying regimens for nonadherent patients; reluctance to intensify regimens for adherent, willing patients; or intensifying regimens for unwilling patients. ${ }^{7,15-21}$ Thus, an objective measure of adherence may provide clinically meaningful guidance for patient-provider discussions about treatment and a means of selecting patients for targeted interventions aimed at improving poor adherence.

The Adherence and Intensification of Medications (AIM) study, which provided pharmacists with CMG through an electronic counseling support tool, demonstrated promising short-term efficacy to lower blood pressure.,9,26 Although blood pressure differences were not sustained, an intervention targeting safety net clinicians could lead to improvements in clinical and patient-important outcomes. The quality of primary care relationships has been strongly associated with adherence. Patient trust in clinicians has been shown to mitigate the impact of financial barriers on patient adherence, and higher quality communication has been associated with lower risk of poor adherence to cardiometabolic and antidepressant medications. ${ }^{12,13,57,58}$ Thus, an intervention specifically including the prescribing provider, particularly in safety net settings, may prove effective in shaping the goals and strategies of medication decision making. 


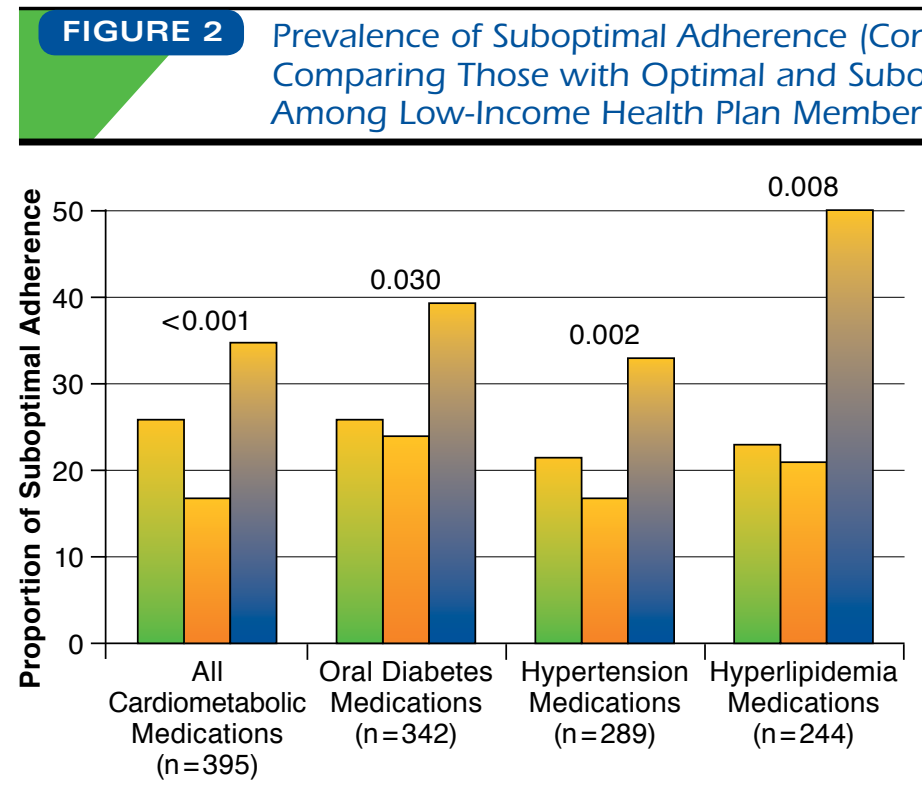
Comparing Those with Optimal and Suboptimal Cardiometabolic Control Among Low-Income Health Plan Members with Diabetes

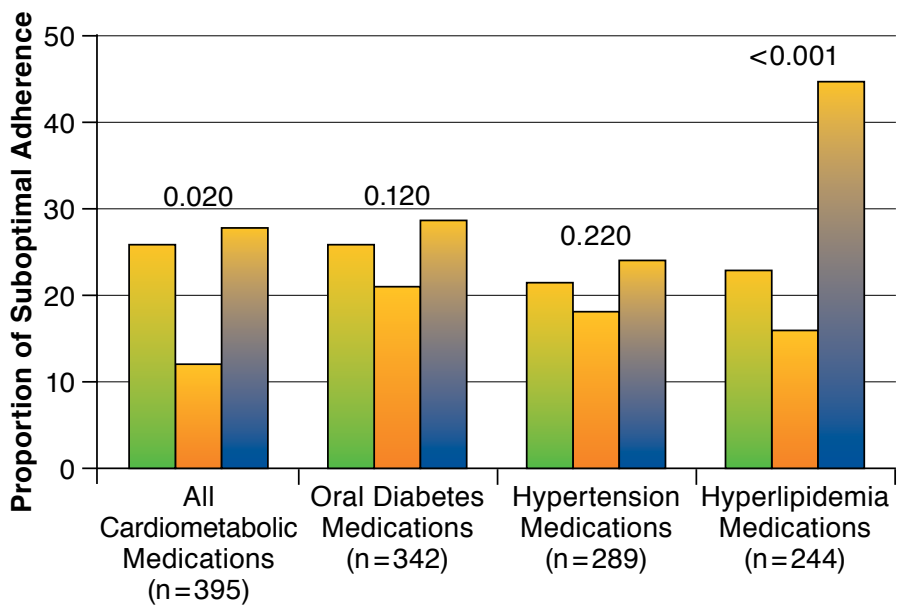

$$
\begin{aligned}
& \square \text { Cohort } \\
& \square \text { Optimal Control-High Cutpoint }{ }^{\mathrm{a}} \\
& \square \text { Suboptimal Control-High Cutpoint }{ }^{\mathrm{a}}
\end{aligned}
$$

\section{$\square$ Cohort \\ $\square$ Optimal Control-Low Cutpoint \\ $\square$ Suboptimal Control-Low Cutpoint ${ }^{\mathrm{b}}$}

aHigh cutpoint suboptimal control: hemoglobin Alc $\geq 9.0 \%$, systolic blood pressure $\geq 140 \mathrm{mmHg}$ and/or diastolic blood pressure $\geq 90 \mathrm{mmHg}$, and low-density lipoprotein $\geq 130 \mathrm{mg} / \mathrm{dL}$. For "all cardiometabolic medications" analysis, suboptimal control occurred on at least 1 measure.

${ }^{b}$ Low cutpoint suboptimal control: hemoglobin Alc $\geq 7.0 \%$, systolic blood pressure $\geq 130 \mathrm{mmHg}$ and/or diastolic blood pressure $\geq 80 \mathrm{mmHg}$, and low-density lipoprotein $\geq 100 \mathrm{mg} / \mathrm{dL}$. For "all cardiometabolic medications" analysis, suboptimal control occurred on at least 1 measure.

$\mathrm{mg} / \mathrm{dL}=$ milligrams per deciliter; $\mathrm{mmHg}=$ millimeter of mercury.

\section{Limitations}

This analysis was a cross-sectional study design and lacked time variables (e.g., length of time since diagnosis and length of treatment). We could not capture CMG for insulin therapy or measure the association between insulin adherence and glycemic control. This is a well-known limitation of CMG.,13,59 Our validity study may be limited by using a CMG cutoff (>20\%) to define nonadherence; however, this choice was based on prior diabetes literature demonstrating that $C M G>20 \%$ is associated with worse cardiometabolic control (Alc, BP, and LDL), and medication possession ratio $<80 \%$ is associated with higher rates of hospitalization. ${ }^{45,46}$ Cardiometabolic data were captured during routine care-thus not measured using standardized methodology or timing-and were not electronically available for all subjects with a calculable CMG. Our estimates for the relationship between CMG and cardiometabolic control may be conservative if missing cardiometabolic measurements were partially due to missed appointments, which is associated with suboptimal control. ${ }^{60}$ Our validity analyses were unadjusted for potentially confounding characteristics, such as comorbidities, diet or lifestyle, and health care utilization.
Our validity analyses cannot also address whether suboptimal control is related to inadequate prescribed therapy, such as lack of treatment intensification by clinicians. We lacked access to electronic prescribing data to allow us to account for provider medication discontinuation, which could have led to overestimation of CMG, but this would have led to a conservative bias regarding the relationship between CMG and cardiometabolic control. Because CMG is not accurate if patients obtain medications through other insurance plans, CMG was not calculable among Medicaid/Medicare dual eligible patients, who comprised $5 \%$ of the sample. Our sample sizes for certain populations (e.g., African-Americans) may have been underpowered to detect differences between the CMG calculable and noncalculable groups, and subgroup analyses were underpowered to detect differences (although the direction of our results was in the hypothesized direction). Our sampling strategy may have excluded certain groups of diabetics, for example, SFHP members with diabetes who denied having diabetes during calls or without sufficient numbers of fills for inclusion; the latter issue may have led us to underestimate the prevalence of nonadher- 
TABLE 3 Prevalence of Suboptimal Adherence Comparing Those with Optimal and Suboptimal Cardiometabolic Control of All Cardiometabolic Measures Combined Among Subgroups of Low-Income Health Plan Members with Diabetes ${ }^{a}$

\begin{tabular}{|c|c|c|c|c|c|c|c|}
\hline & \multirow[b]{2}{*}{$\begin{array}{c}\text { Cohort } \\
(\%)\end{array}$} & \multicolumn{3}{|c|}{ Low Cutpoint (\%) ${ }^{b}$} & \multicolumn{3}{|c|}{ High Cutpoint (\%)c } \\
\hline & & $\begin{array}{l}\text { Optimal } \\
\text { Control }\end{array}$ & $\begin{array}{l}\text { Suboptimal } \\
\text { Control }\end{array}$ & $P$ Value & $\begin{array}{l}\text { Optimal } \\
\text { Control }\end{array}$ & $\begin{array}{l}\text { Suboptimal } \\
\text { Control }\end{array}$ & $P$ Value \\
\hline Aged $<55$ years $(n=155)$ & 31.6 & 15.4 & 33.1 & 0.230 & 25.4 & 32.9 & 0.340 \\
\hline Aged $\geq 55$ years $(n=240)$ & 22.1 & 11.1 & 24.0 & 0.090 & 12.1 & 35.9 & $<0.001$ \\
\hline Female $(\mathrm{n}=269)$ & 25.7 & 18.2 & 26.7 & 0.290 & 17.8 & 32.1 & 0.009 \\
\hline Male $(n=126)$ & 26.2 & 0.0 & 30.0 & 0.010 & 14.1 & 40.0 & 0.002 \\
\hline Cantonese $(n=188)$ & 17.0 & 10.7 & 18.1 & 0.420 & 14.6 & 17.9 & 0.550 \\
\hline English $(\mathrm{n}=153)$ & 32.7 & 16.7 & 34.8 & 0.120 & 20.6 & 42.9 & 0.006 \\
\hline Spanish $(n=54)$ & 37.0 & 0.0 & 39.2 & 0.290 & 15.4 & 56.0 & 0.002 \\
\hline Asian $(n=241)$ & 19.5 & 11.8 & 20.8 & 0.220 & 16.7 & 21.8 & 0.340 \\
\hline Hispanic $(\mathrm{n}=74)$ & 39.2 & 20.0 & 40.6 & 0.640 & 20.0 & 51.4 & 0.008 \\
\hline White $(n=47)$ & 25.5 & 0.0 & 30.0 & 0.170 & 11.5 & 42.1 & 0.030 \\
\hline Black $(n=21)$ & 42.9 & 50.0 & 42.1 & 1.000 & 28.6 & 45.5 & 0.640 \\
\hline Other $(n=12)$ & 42.9 & 0.0 & 45.5 & 1.000 & 0.0 & 62.5 & 0.080 \\
\hline Healthy Worker/Healthy San Francisco plan $(n=301)$ & 22.3 & 12.2 & 23.9 & 0.100 & 14.8 & 31.9 & $<0.001$ \\
\hline Medicaid $(\mathrm{n}=90)$ & 36.7 & 12.5 & 39.0 & 0.250 & 26.7 & 40.0 & 0.230 \\
\hline Commercial/uninsured $(n=4)$ & 50.0 & 0.0 & 50.0 & N/Ac & 0.0 & 50.0 & N/A \\
\hline
\end{tabular}

a Suboptimal adherence: continuous medication gap $>20 \%$.

${ }^{b}$ Low cutpoint suboptimal control: hemoglobin Alc $\geq 7.0 \%$, systolic blood pressure $\geq 130 \mathrm{mmHg}$ and/or diastolic blood pressure $\geq 80 \mathrm{mmHg}$, and low-density lipoprotein $\geq 100 \mathrm{mg} / \mathrm{dL}$.

'High cutpoint suboptimal control: hemoglobin Alc $\geq 9.0 \%$, systolic blood pressure $\geq 140 \mathrm{mmHg}$ and/or diastolic blood pressure $\geq 90 \mathrm{mmHg}$, and low-density lipoprotein $\geq 130 \mathrm{mg} / \mathrm{dL}$.

${ }^{d} \mathrm{~N} / \mathrm{A}=$ not available, since the 4 health plan members had suboptimal control with low and high cutpoints.

$m g / d L=$ milligrams per deciliter; $m m H g=$ millimeter of mercury.

ence. Finally, these results may not be generalizable to other Medicaid managed care or safety net populations, with our high proportion of Asian and Cantonese-speaking health plan members and low proportion of African-American members. However, the diversity of the included population is a strength of this analysis, given the expansion of Medicaid to include more linguistically diverse populations. ${ }^{27-31}$

\section{Conclusions}

CMG demonstrated acceptable inclusiveness and validity in a diverse, low-income safety net population, comparable with its performance in other insured populations. Applying CMG to Medicaid and low-income health plan pharmacy claims may provide a useful tool for safety net health care systems to measure adherence among linguistically and culturally diverse populations. Future research should explore how the inclusiveness, selectivity, and validity of CMG change with the implementation of the Affordable Care Act. In addition, future translational research should rigorously examine whether harnessing CMG as a clinical indicator of adherence can guide clinical interventions and measurably improve outcomes among safety net populations.

\section{Authors}

NEDA RATANAWONGSA, MD, MPH, is Associate Professor; JUDY QUAN, PhD, is Biostatistician; URMIMALA SARKAR, MD, $\mathrm{MPH}$, is Associate Professor; and DEAN SCHILLINGER, MD, is Professor, Division of General Internal Medicine and UCSF Center for Vulnerable Populations at San Francisco General Hospital and Trauma Center, University of California, San Francisco. MARGARET HANDLEY, PhD, MPH, is Associate Professor, Department of Epidemiology and Biostatistics, University of California, San Francisco. ANDREW J. KARTER, PhD, is Senior Investigator; Melissa M. Parker, MS, is Researcher; and JULIE A. SCHMITTDIEL, PhD, is Research Scientist, Kaiser Division of Research, Kaiser Permanente, Oakland, California.

AUTHOR CORRESPONDENCE: Neda Ratanawongsa, MD, MPH, Associate Professor of Medicine, Division of General Internal Medicine, UCSF Center for Vulnerable Populations at San Francisco General Hospital and Trauma Center, 1001 Potrero Ave., Box 1364, San Francisco CA 94110. Tel.: 415.206.3188; Fax: 415.206.5586; E-mail: neda.ratanawongsa@ucsf.edu. 


\section{Reach and Validity of an Objective Medication Adherence Measure Among Safety Net Health Plan Members with Diabetes: A Cross-Sectional Study}

\section{DISCLOSURES}

The San Francisco Health Plan participated in the design and implementation of the intervention and evaluation from which this study was drawn. This study was funded by Health Delivery Systems Center for Diabetes Translational Research (CDTR) through NIDDK grant 1P30-DK092924, R01DK080726, and R01-DK081796; the Agency for Healthcare Research and Quality grants R18HS017261, 1R03HS020684-01, and K08HS022561-01; and the McKesson Foundation. NIH grant UL1 RR024131 supports the UCSF Collaborative Research Network. Research reported in this publication was supported by the National Center for Advancing Translational Sciences of the NIH under Award Number KL2TR000143.

The content of this article is solely the responsibility of the authors and do not necessarily represent the official views of AHRQ or the NIH. The funders had no role in the study design; collection, analysis, and interpretation of data; writing of the manuscript; approval of the manuscript; or decision to submit the manuscript for publication. None of the authors had conflicts of interest.

All authors contributed to the conception and design and drafting and critical revision of the manuscript, including final approval of the version to be published.

\section{REFERENCES}

1. Agency for Healthcare Research and Quality. 2010 National healthcare disparities report. AHRQ Publication No.11-0005. March 2011. Available at: http://www.ahrq.gov/research/findings/nhqrdr/nhdr10/nhdrl0.pdf. Accessed June 21, 2015.

2. Sequist TD, Fitzmaurice GM, Marshall R, Shaykevich S, Safran DG, Ayanian JZ. Physician performance and racial disparities in diabetes mellitus care. Arch Intern Med. 2008;168(11):1145-51.

3. Trivedi AN, Zaslavsky AM, Schneider EC, Ayanian JZ. Relationship between quality of care and racial disparities in Medicare health plans. JAMA. 2006;296(16):1998-2004.

4. American Diabetes Association. Standards of medical care in diabetes2012. Diabetes Care. 2012;35(Suppl 1):S11-63.

5. Kerr EA, Zikmund-Fisher BJ, Klamerus ML, Subramanian U, Hogan MM, Hofer TP. The role of clinical uncertainty in treatment decisions for diabetic patients with uncontrolled blood pressure. Ann Intern Med. 2008;148(10):717-27.

6. Heisler M, Hogan MM, Hofer TP, Schmittdiel JA, Pladevall M, Kerr EA. When more is not better: treatment intensification among hypertensive patients with poor medication adherence. Circulation. 2008;117(22):2884-92

7. Schmittdiel JA, Uratsu CS, Karter AJ, et al. Why don't diabetes patients achieve recommended risk factor targets? Poor adherence versus lack of treatment intensification. J Gen Intern Med. 2008;23(5):588-94.

8. Karter AJ, Parker MM, Moffet HH, Ahmed AT, Schmittdiel JA, Selby JV. New prescription medication gaps: a comprehensive measure of adherence to new prescriptions. Health Serv Res. 2009;44(5 Pt 1):1640-61.

9. Heisler M, Hofer TP, Schmittdiel JA, et al. Improving blood pressure control through a clinical pharmacist outreach program in patients with diabetes mellitus in 2 high-performing health systems: the adherence and intensification of medications cluster randomized, controlled pragmatic trial. Circulation. 2012;125(23):2863-72.

10. Krahn M, Naglie G. The next step in guideline development: incorporating patient preferences. JAMA. 2008;300(4):436-38

11. Montori VM, Fernandez-Balsells M. Glycemic control in type 2 diabetes: time for an evidence-based about-face? Ann Intern Med. 2009;150(11):803-08.

12. Bauer AM, Parker MM, Schillinger D, et al. Associations between antidepressant adherence and shared decision-making, patient-provider trust, and communication among adults with diabetes: Diabetes Study of Northern California (DISTANCE). J Gen Intern Med. 2014;29(8):1139-47.
13. Ratanawongsa N, Karter AJ, Parker MM, et al. Communication and medication refill adherence: the Diabetes Study of Northern California. JAMA Intern Med. 2013;173(3):210-18.

14. Meddings J, Kerr EA, Heisler M, Hofer TP. Physician assessments of medication adherence and decisions to intensify medications for patients with uncontrolled blood pressure: still no better than a coin toss. BMC Health Serv Res. 2012;12(1):270.

15. Grant RW, Pabon-Nau L, Ross KM, Youatt EJ, Pandiscio JC, Park ER. Diabetes oral medication initiation and intensification: patient views compared with current treatment guidelines. Diabetes Educ. 2011;37(1):78-84.

16. Montori VM, Gafni A, Charles C. A shared treatment decision-making approach between patients with chronic conditions and their clinicians: the case of diabetes. Health Expect. 2006;9(1):25-36.

17. Elwyn G, Hutchings H, Edwards A, et al. The OPTION scale: measuring the extent that clinicians involve patients in decision-making tasks. Health Expect. 2005;8(1):34-42.

18. Kraetschmer N, Sharpe N, Urowitz S, Deber RB. How does trust affect patient preferences for participation in decision-making? Health Expect. 2004;7(4):317-26

19. McCaffery KJ, Smith SK, Wolf M. The challenge of shared decision making among patients with lower literacy: a framework for research and development. Med Decis Making. 2010;30(1):35-44.

20. Makoul G, Clayman ML. An integrative model of shared decision making in medical encounters. Patient Educ Couns. 2006;60(3):301-12.

21. Saba GW, Wong ST, Schillinger D, et al. Shared decision making and the experience of partnership in primary care. Ann Fam Med. 2006;4(1):54-62.

22. Steiner JF, Prochazka AV. The assessment of refill compliance using pharmacy records: methods, validity, and applications. J Clin Epidemiol. 1997;50(1):105-16.

23. Steiner JF, Koepsell TD, Fihn SD, Inui TS. A general method of compliance assessment using centralized pharmacy records. Description and validation. Med Care. 1988;26(8):814-23.

24. Choo PW, Rand CS, Inui TS, et al. Validation of patient reports, automated pharmacy records, and pill counts with electronic monitoring of adherence to antihypertensive therapy. Med Care. 1999;37(9):846-57.

25. Bryson CL, Au DH, Young B, McDonell MB, Fihn SD. A refill adherence algorithm for multiple short intervals to estimate refill compliance (ReComp). Med Care. 2007;45(6):497-504.

26. Heisler M, Hofer TP, Klamerus ML, et al. Study protocol: the Adherence and Intensification of Medications (AIM) study-a cluster randomized controlled effectiveness study. Trials. 2010;11:95.

27. Sommers BD, Tomasi MR, Swartz K, Epstein AM. Reasons for the wide variation in Medicaid participation rates among states hold lessons for coverage expansion in 2014. Health Aff (Millwood). 2012;31(5):909-19.

28. Martin LT, Parker RM. Insurance expansion and health literacy. JAMA. 2011;306(8):874-75

29. Sentell T. Implications for reform: survey of California adults suggests low health literacy predicts likelihood of being uninsured. Health Aff (Millwood). 2012;31(5):1039-48.

30. Maxwell J, Cortes DE, Schneider KL, Graves A, Rosman B. Massachusetts' health care reform increased access to care for Hispanics, but disparities remain. Health Aff (Millwood). 2011;30(8):1451-60.

31. Pande AH, Ross-Degnan D, Zaslavsky AM, Salomon JA. Effects of healthcare reforms on coverage, access, and disparities: quasi-experimental analysis of evidence from Massachusetts. Am J Prev Med. 2011;41(1):1-8.

32. Collins SR, Robertson R, Garber T, Doty MM. Gaps in health insurance: why so many Americans experience breaks in coverage and how the Affordable Care Act will help: findings from the Commonwealth Fund Health Insurance Tracking Survey of U.S. Adults, 2011. Issue Brief (Commonw Fund). 2012;9:1-22. 
33. Hall AG, Harman JS, Zhang J. Lapses in Medicaid coverage: impact on cost and utilization among individuals with diabetes enrolled in Medicaid. Med Care. 2008;46(12):1219-25.

34. Hargraves JL. Trends in health insurance coverage and access among black, Latino and white Americans, 2001-2003. Track Rep. 2004;(11):1-6.

35. Ratanawongsa N, Handley MA, Quan J, et al. Quasi-experimental trial of diabetes self-management automated and real-time telephonic support (SMARTSteps) in a Medicaid managed care plan: study protocol. BMC Health Serv Res. 2012;12(1):22.

36. Ratanawongsa N, Handley MA, Sarkar U, et al. Diabetes health information technology innovation to improve quality of life for health plan members in urban safety net. J Ambul Care Manage. 2014;37(2):127-37.

37. American Diabetes Association. Standards of medical care in diabetes-2009. Diabetes Care. 2009;32(Suppl 1):S13-61.

38. Wilson E, Chen AH, Grumbach K, Wang F, Fernandez A. Effects of limited English proficiency and physician language on health care comprehension. J Gen Intern Med. 2005;20(9):800-06.

39. Sarkar U, Schillinger D, Lopez A, Sudore R. Validation of self-reported health literacy questions among diverse English and Spanish-speaking populations. J Gen Intern Med. 2011;26(3):265-71.

40. Chew LD, Griffin JM, Partin MR, et al. Validation of screening questions for limited health literacy in a large VA outpatient population. J Gen Intern Med. 2008;23(5):561-66.

41. Long SK, Kenney GM, Zuckerman S, et al. The health reform monitoring survey: addressing data gaps to provide timely insights into the Affordable Care Act. Health Aff (Millwood). 2014;33(1):161-67.

42. Politi MC, Kaphingst KA, Kreuter M, Shacham E, Lovell MC, McBride T. Knowledge of health insurance terminology and details among the uninsured. Med Care Res Rev. 2014;71(1):85-98.

43. Hansen JS, Wallace LS, DeVoe JE. How readable are Spanish-language Medicaid applications? J Immigr Minor Health. 2011;13(2):293-98.

44. Pati S, Kavanagh JE, Bhatt SK, Wong AT, Noonan K, Cnaan A. Reading level of Medicaid renewal applications. Acad Pediatr. 2012;12(4):297-301.

45. Pladevall M, Williams LK, Potts LA, Divine G, Xi H, Lafata JE. Clinical outcomes and adherence to medications measured by claims data in patients with diabetes. Diab Care. 2004;27(12):2800-05.

46. Lau DT, Nau DP. Oral antihyperglycemic medication nonadherence and subsequent hospitalization among individuals with type 2 diabetes. Diab Care. 2004:27(9):2149-53.
47. Bauer AM, Schillinger D, Parker MM, et al. Health literacy and antidepressant medication adherence among adults with diabetes: the Diabetes Study of Northern California (DISTANCE). J Gen Intern Med. 2013;28(9):1181-87.

48. Osborn CY, Cavanaugh K, Wallston KA, et al. Health literacy explains racial disparities in diabetes medication adherence. J Health Commun. 2011;16(Suppl 3):268-78.

49. Robbins L, Robbins ES, Katz SE, Geliebter B, Stern M. Achievement motivation in medical students. J Med Educ. 1983;58(11):850-58.

50. Schillinger D, Machtinger EL, Wang F, et al. Language, literacy, and communication regarding medication in an anticoagulation clinic: are pictures better than words? In: Henriksen K, Battles JB, Marks ES, Lewin DI, eds. Advances in Patient Safety: From Research to Implementation. Vol. 2. Rockville, MD: Agency for Healthcare Research and Quality; 2005. 51. Zargarzadeh AH, Law AV. Access to multilingual prescription labels and verbal translation services in California. Res Social Adm Pharm. 2011;7(4):338-46

52. Hess LM, Raebel MA, Conner DA, Malone DC. Measurement of adherence in pharmacy administrative databases: a proposal for standard definitions and preferred measures. Ann Pharmacother. 2006;40(7-8):1280-88.

53. Adams AS, Trinacty CM, Zhang F, et al. Medication adherence and racial differences in Alc control. Diabetes Care. 2008;31(5):916-21.

54. Pladevall M, Williams LK, Potts LA, Divine G, Xi H, Lafata JE. Clinical outcomes and adherence to medications measured by claims data in patients with diabetes. Diabetes Care. 2004;27(12):2800-05.

55. Karter AJ, Subramanian U, Saha C, et al. Barriers to insulin initiation: the translating research into action for diabetes insulin starts project. Diabetes Care. 2010;33(4):733-35

56. Vijan S, Hayward RA, Ronis DL, Hofer TP. Brief report: the burden of diabetes therapy: implications for the design of effective patient-centered treatment regimens. J Gen Intern Med. 2005;20(5):479-82.

57. Lee YY, Lin JL. The effects of trust in physician on self-efficacy, adherence and diabetes outcomes. Soc Sci Med. 2009;68(6):1060-68.

58. Piette JD, Heisler M, Krein S, Kerr EA. The role of patient-physician trust in moderating medication nonadherence due to cost pressures. Arch Intern Med. 2005;165(15):1749-55.

59. Katon W, Russo J, Lin EH, et al. Diabetes and poor disease control: is comorbid depression associated with poor medication adherence or lack of treatment intensification? Psychosom Med. 2009;71(9):965-72.

60. Karter AJ, Parker MM, Moffet HH, et al. Missed appointments and poor glycemic control: an opportunity to identify high-risk diabetic patients. Med Care. 2004;42(2):110-15. 